\title{
TINGKAT ANSIETAS PADA PASIEN HIPERTENSI PRIMER DI RSUD ABDUL WAHAB SJAHRANIE KALIMANTAN TIMUR
}

\author{
Made Ermayani \\ Program Studi DIII Keperawatan STIKES Dirgahayu Samarinda \\ J1.Pasundan No 21, Samarinda \\ ermayani.made@gmail.com
}

\begin{abstract}
ABSTRAK
Hipertensi merupakan penyakit kronis yang jika tidak dapat dikelola dengan tepat dapat meningkatkan risiko untuk pengembangan gangguan kesehatan mental khususnya ansietas dan depresi. Tujuan penelitian adalah mengetahui tingkat ansietas pada pasien hipertensi primer. Penelitian merupakan penelitian kuantitatif dengan jenis penelitian adalah penelitian deskriptif. Pengumpulan data menggunakan kuisioner Hamilton Anxiety Scale (HARS). Populasi penelitian ini adalah semua pasien hipertensi yang berkunjung ke Instalasi Rawat Jalan dan Poliklinik Jantung di RSUD Abdul Wahab Sjahranie dengan jumlah sampel adalah 91 responden. Hasil penelitian menunjukan bahwa tingkat ansietas responden mayoritas termasuk dalam ansietas ringan sebanyak 48 responden (52,7\%). Pasien hipertensi primer lebih banyak mengalami tingkat ansietas ringan.
\end{abstract}

Kata kunci: hipertensi primer, ansietas

\section{PENDAHULUAN}

Hipertensi merupakan kondisi dimana terdapat peningkatan tekaanan darah sistolik >140 $\mathrm{mmHg}$ dan tekanan darah diastolic $>90 \mathrm{mmHg}$. Penyakit hipertensi merupakan salah satu penyakit yang tidak hanya berdampak secara fisik tapi juga dapat mempengaruhi kondisi psikologis, karena pengobatan hipertensi yang seumur hidup dan tidak bisa sembuh. Pasien dengan kondisi kronis seperti hipertensi mengalami banyak emosi negatif yang meningkatkan risiko untuk pengembangan gangguan kesehatan mental khususnya ansietas dan depresi (Kretchy et al., 2014; Dejean et al \& Vetere et al dalam Kretchy et al., 2014).

Zhang Fan et al (2005) dan Liao et al (2014) menemukan bahwa prevalensi ansietas lebih tinggi daripada depresi $(38,5 \%$ vs $5,7 \%$ dan $23,3 \%$ vs $5,7 \%)$ serta beberapa faktor risiko ansietas pada pasien hipertensi yaitu pengobatan yang tidak teratur, merokok, pekerja kasar, hipertensi stadium 1 dan 2 , jenis kelamin perempuan, usia muda, tingkat pendidikan, dan pendapatan yang rendah. Penelitian Kretchy et al (2014) juga menambahkan bahwa pasien hipertensi lebih banyak mengalami gejala ansietas (56\%), daripada stres (20\%) dan depresi (4\%). Pada penelitiannya dijelaskan bahwa hipertensi menuntut kepatuhan pasien terhadap pengobatan anti-hipertensi yang berdampak pada kondisi psikologis. Meskipun hipertensi merupakan masalah biomedis, kondisi pasien dengan tuntutan hidup yang tinggi dari penyakit hipertensi mengakibatkan masalah kesehatan mental.

Cheung et al (2005) menjelaskan bahwa ansietas dan hipertensi merupakan dua hal yang saling mempengaruhi. Hipertensi dapat menyebabkan gangguan psikologis seperti ansietas, dan masalah psikologis juga dapat menjadi faktor risiko yang mengembangkan hipertensi. Cheung et al (2005) juga menjelaskan bahwa banyak peneliti telah mempelajari faktorfaktor psikologis yang dapat menyebabkan hipertensi yaitu: (1) Rutledge dan Hogan 
(2002) menemukan bahwa risiko terkena hipertensi adalah sekitar $8 \%$ lebih tinggi pada orang dengan tekanan psikologis berat dibandingkan dengan tekanan psikologis yang minimal. Orang yang menderita depresi berat atau ansietas memiliki risiko dua sampai tiga kali terkena hipertensi; (2) Studi di Perancis pada orang lanjut usia mengungkapkan bahwa hipertensi dikaitkan dengan ansietas tetapi tidak depresi.

Penelitian ini merupakan penelitian kuantitatif dengan jenis penelitian adalah penelitian deskriptif yaitu untuk mengetahui gambaran tingkat ansietas pada hipertensi primer. Penelitian dilaksanakan di Instalasi Rawat Jalan (IRJA) dan Poliklinik Jantung RSUD Abdul Wahab Sjahranie (AWS), Kalimantan Timur. Populasi penelitian ini adalah semua pasien hipertensi yang berkunjung ke Instalasi Rawat Jalan (IRJA) dan Poliklinik Jantung di RSUD A.W. Sjahranie mulai minggu ketiga bulan April sampai dengan minggu kedua bulan Mei 2015. Jumlah keseluruhan responden adalah 91 responden.

Pengumpulan data menggunakan instrumen yaitu instrumen pengukuran tekanan darah yaitu menggunakan tensimeter air aneroid merek onemed dan stetoskop; lembar observasi yang terdiri dari lembar observasi tekanan darah untuk menuliskan hasil pengumpulan data yang didapat dari hasil pengukuran; dan kuisioner Hamilton Anxiety Scale (HARS). Kuisioner baku yang digunakan pada penelitian ini bertujuan untuk mengkaji tingkat kecemasan yaitu The Hamilton Anxiety Rating Scale (HARS).

\section{HASIL}

\section{A. Karakteristik Responden}

Hasil penelitian berdasarkan usia responden menunjukan bahwa mayoritas responden yaitu sebanyak 40 respoden (44\%) berada pada rentang usia 56-65 tahun. Data ini menunjukan bahwa penderita hipertensi yang paling besar adalah usia lansia awal dan akhir menurut
Depkes, atau usia middle age dan elderly menurut WHO, yaitu sebanyak 86,9\%. Hasil penelitian ini sesuai dengan survey epidemiologi yang dilakukan oleh Babatsikou \& Zavitsanou (2010) di Amerika Serikat dan Eropa, menyimpulkan bahwa prevalensi hipertensi di usia elderly antara 53\% dan 72\%. Penelitian oleh Zhaoqing Sun et al (2010) juga menemukan bahwa rata-rata insiden hipertensi pada penduduk Cina usia middle age adalah 48,21 tahun pada laki-laki dan 47,86 tahun pada perempuan. WHO menambahkan bahwa di seluruh dunia pada tahun 2008 sekitar $40 \%$ orang dewasa yang berusia diatas 25 tahun terdiagnosa hipertensi.

Hasil penelitian berdasarkan jenis kelamin responden menunjukan bahwa responden dengan jenis kelamin perempuan lebih banyak daripada jenis kelamin lakilaki yaitu sebanyak 52 respoden $(57,1 \%)$. Data ini menunjukan bahwa perempuan mempunyai kecenderungan lebih besar untuk menderita hipertensi. Hal ini sesuai dengan penelitian oleh Kwok Leung Ong et al (2008) yang menjelaskan bahwa prevalensi tekanan darah yang tidak terkontrol pada wanita adalah pada usia $55,9 \pm 1,5 \%$. Penelitian retrospektif oleh Robitaile et al (2012) juga menemukan bahwa dari 26 juta orang, insiden hipertensi pada usia diatas 60 tahun lebih banyak pada wanita daripada laki-laki..

Hasil penelitian berdasarkan tingkat pendidikan responden menunjukan bahwa mayoritas responden berada pada tingkat pendidikan dasar (SD atau SMP sederajat) yaitu sebanyak 56 respoden $(61,5 \%)$. Hal ini sesuai hasil statistik dimana tingkat pendidikan kepala rumah tangga di Kalimantan Timur mayoritas tidak tamat SD dan SD yaitu mencapai 67,82 persen (Kuncona, 2012). Faktor geografis wilayah Kalimantan Timur menyebabkan masyarakat yang tinggal dipedalaman dan terpencil mengalami kesulitan untuk mendapatkan akses pendidikan. Kualitas pendidikan mulai ditingkatkan semenjak 
adanya otonomi pendidikan (Saripati Ita, 2007).

Hasil penelitian berdasarkan kebiasaan merokok responden menunjukan bahwa mayoritas responden merupakan perokok pasif yaitu sebanyak 36 respoden $(39,6 \%)$. Perokok pasif dalam penelitian ini adalah responden berada dalam satu tempat tinggal dengan perokok aktif, dimana berdasarkan hasil wawancara perokok aktifnya adalah suami, anak, dan atau menantu. Hasil penelitian ini berkaitan dengan mayoritas responden yang berjenis kelamin perempuan, dimana pada umumnya perempuan tidak memiliki kebiasaan merokok, tapi responden selalu terpapar dengan asap rokok. Aurelio (2011) menjelaskan bahwa terdapat hubungan antara paparan rokok dengan meningkatnya tekanan darah. Beberapa observasi menunjukan bahwa terdapat peningkatan tekanan darah ketika merokok atau terpapar rokok secara pasif.

Hasil penelitian berdasarkan tingkat social ekonomi responden menunjukan bahwa, mayoritas tingkat sosial ekonomi responden berada pada tingkat sosial ekonomi rendah (penghasilan kurang dari Rp. 2.000.000/bulan) yaitu sebanyak 56 respoden $(61,5 \%)$. Penelitian oleh Abed \& Abdul-Haddaf (2013) menemukan bahwa hipertensi secara bermakna dikaitkan dengan rendahnya status sosial ekonomi dan pekerjaan. Hal ini didukung oleh hasil meta analisis Leng Bing et al (2015) bahwa meningkatnya resiko hipertensi berdasarkan tingkat sosial ekonomi terkait dengan pendapatan, pekerjaan dan pendidikan. Tingkat sosial ekonomi yang rendah mempunyai hubungan yang positif dengan tingginya tekanan darah dan meningkatnya risiko hipertensi pada individu yang memiliki tingkat sosial ekonomi yang rendah paling banyak terjadi pada perempuan.

\section{B. Tingkat Ansietas}

Tabel 1. Tingkat Ansietas Pasien Hipertensi Primer

\begin{tabular}{llcc}
\hline No & $\begin{array}{c}\text { Karakteristik } \\
\text { Ansietas }\end{array}$ & \multicolumn{2}{l}{ Jumlah } \\
& & $\mathrm{n}$ & $(\%)$ \\
\hline 1. & Ringan & 48 & $(52,7)$ \\
2. & Sedang & 30 & $(33)$ \\
3. & Berat & 13 & $(14,3)$ \\
\hline & $\quad$ Jumlah & 91 & $(100)$ \\
\hline
\end{tabular}

Tabel 1. menjelaskan bahwa mayoritas tingkat ansietas responden termasuk dalam ansietas ringan yaitu sebanyak 48 responden (52,7\%). Responden penelitian ini adalah pasien dengan hipertensi primer. Das (2008) menjelaskan bahwa hipertensi merupakan salah satu penyakit kronis yang tidak dapat disembuhkan, hanya mampu dicegah perkembangannya melalui modifikasi faktor risiko terjadinya hipertensi (dikutip dalam Sujatha \& Judhi, 2014). Kretchy et al (2014) menambahkan bahwa hipertensi menuntut kepatuhan pasien terhadap pengobatan anti-hipertensi yang berdampak pada kondisi psikologis. Meskipun hipertensi merupakan masalah biomedis, kondisi pasien dengan tuntutan hidup dari penyakit hipertensi mengakibatkan masalah kesehatan mental. Pasien dengan kondisi kronis seperti hipertensi mengalami banyak emosi negatif yang meningkatkan risiko untuk pengembangan gangguan kesehatan mental khususnya ansietas dan depresi.

Stuart (2009) menjelaskan bahwa kesehatan individu memiliki efek nyata sebagai presipitasi terjadinya ansietas. Apabila kesehatan individu terganggu, maka kemampuan individu untuk mengatasi ancaman berupa penyakit (gangguan fisik) akan menurun dan juga menimbulkan stres psikologis. Stres psikologis yang tidak bisa diatasi oleh individu, akan menyebabkan munculnya 
ansietas sampai dengan depresi. Beberapa penelitian membuktikan bahwa individu yang mengalami gangguan fisik khususnya hipertensi lebih banyak mengalami ansietas daripada depresi. Penelitian oleh Zhang Fan et al (2005) dan Liao et al (2014) menemukan bahwa prevalensi ansietas pada pasien hipertensi lebih besar tinggi daripada depresi $(38,5 \%$ vs $5,7 \%$ dan $23,3 \%$ vs 5,7\%). Bahkan Kretchy et al (2014) juga menemukan bahwa pasien hipertensi lebih banyak mengalami ansietas $(56 \%)$ daripada stres $(20 \%)$ dan depresi $(4 \%)$.

Respon fisiologi yang berhubungan dengan ansietas adalah stimulus pada hipotalamus yaitu glandula adrenal dan pengaktifan sistem saraf otonom. Respon Sistem saraf otonom berespon terhadap ansietas secara tidak sadar yang merupakan bagian dari respon tubuh untuk pertahanan diri. Saraf otonom dan hormon epinefrin atau adrenalin menyebabkan perubahan pada tanda-tanda vital sebagai persiapan mekanisme pertahanan tubuh. Glandula adrenal mengeluarkan hormon adrenalin atau epinephrin yang menyebabkan peningkatan kebutuhan oksigen, dilatasi pupil dan peningkatan tekanan arteri dan denyut jantung, dan peningkatan glikogenolisis. Jika kondisi berbahaya atau ansietas sudah selesai, maka saraf parasimpatis yang bekerja dan mengembalikan tubuh dalam kondisi normal kembali (Videbeck, 2008 dalam Ermayani, Prabawati, Susilo, 2020 ; Stuart 2009 dalam Ermayani, Prabawati, Susilo, 2020).

\section{KESIMPULAN DAN SARAN}

\section{A. Kesimpulan}

1. Karakteristik responden mayoritas : (1) $44,0 \%$ responden berusia $56-65$ tahun; (2) $57,1 \%$ responden perempuan; (3) $61,5 \%$ responden dengan tingkat pendidikan dasar; (4) $39,6 \%$ responden merupakan perokok pasif dan (4) $61,5 \%$ responden berada pada tingkat sosial ekonomi rendah.

2. Tingkat ansietas responden mayoritas termasuk dalam ansietas ringan sebanyak 48 responden $(52,7 \%)$.

\section{B. SARAN}

1. Bagi Pendidik dan civitas akademika

Hasil penelitian ini dapat dijadikan bahan tambahan untuk pengembangan teori hipertensi terkait tentang ansietas.

2. Bagi Peneliti Selanjutnya

Peneliti selanjutnya dapat menganalisis lebih dalam tentang hubungan atau pengaruh faktor ansietas terhadap tekanan darah.

\section{DAFTAR PUSTAKA}

Abed \& Abdul-Haddaf. (2013). Risk Factors of Hypertension at UNRWA Primary Health Care Centers in Gaza Governorates. Hindawi Publishing Corporation, ISRN Epidemiology Volume 2013. Diperoleh pada tanggal 1 Februari 2015 dari www.hindawi.com.

Aurelio L. (2011). Smoking and Hypertension: Independent or Additive Effects to Determining Vascular Damage?Current Vascular Pharmacology, Volume 9, Number 5, pages 585-593. Diperoleh tanggal 8 Agustus 2015 dari www.ingentaconnect.com

Babatsikou \& Zavitsanou. (2010). Epidemiology of hypertension in the elderly. Health Science Journal, Volume 4, Issue 1. Diperoleh pada tanggal 1 November 2014 dari hsj.gr/download.

Cheung et al. (2005). The Relationship Between Hypertension And Anxiety Or Depression In Hong Kong Chinese. Experimental Clinical Cardiology Volume 10, Number. 
Diperoleh pada tanggal 16 Januari 2015 dari www.ncbi.nlm.nih.gov.

Ermayani Made, Prabawati Dewi, Susilo Wilhelmus Hary. 2020. The Effect Of Progressive Muscle Relaxation On Anxiety And Blood Pressure Among Hypertension Patients In East Kalimantan, Indonesia. Enfermería Clínica, Vol. 30. Issue S7, 3rd Udayana International Nursing Conference.Global Health: Escalating Evidence Transformation into Practice, pages 121-125 (December 2020). Di akses dari https://www.elsevier.es/en-revistaenfermeria-clinica-35-articulo-theeffect-progressive-muscle-relaxationS1130862120304757

Kretchy IA, Owusu-Daaku FT, Danquah SA (2014). Mental health in hypertension: Assessing symptoms of anxiety, depression and stress on antihypertensive medication adherence. Int J Ment Health Syst. ;8(1):1-6.

Kwok Leung Ong, et al. (2008). Gender Difference in Blood Pressure Control and Cardiovascular Risk Factors in Americans With Diagnosed Hypertension. Hypertension Journal, Volume 51, pages 1142-1148. Diperoleh pada tanggal 20 Agustus 2015 dari hyper.ahajournals.org

Leng, Bing et al. (2015). Socioeconomic Status and Hypertension: A Metaanalysis. Journal of hypertension, Volume 33, Issue 2, pages 221-229. Diperoleh tanggal 8 Agustus 2015 dari http://journals.lww.com/

Liao et al. (2014). Prevalence And Related Risk Factors Of Hypertensive Patients With Co-Morbid Anxiety And/Or Depression In Community: A Cross-Sectional Study. Zhonghua Yi Xue Za Zhi, Volume 7; 94(1):62-6. Diperoleh pada tanggal 4 Februari 2015 dari www.ncbi.nlm.nih.gov
Robitaille et al. (2012). Diagnosed Hypertension In Canada: Incidence, Prevalence And Associated Mortality. Canadian Medical Association Journal, Volume 184, Issue 1, Pages 49-56. Diperoleh pada tanggal 11 Januari 2015 dari www.ncbi.nlm.nih.gov

Singh et al. (2011). Prevalence And Risk Factors For Prehypertension And Hypertension In Five Indian Cities. Acta Cardiology Volume 66 Issue 1 Pages 29-37. Diperoleh pada tanggal $1 \quad$ Februari 2015 dari www.ncbi.nlm.nih.gov

Zhang Fan et al. (2005). Prevalence And Risk Factors of Anxiety And Depression In Hypertensive Patients. Journal of Capital Medical University, Volume 26, Issue 2, Pages 140-142. Diperoleh pada tanggal 4 Februari 2015 dari http://xuebao.ccmu.edu.cn 